\title{
Observation of the seismic mode "drumbeats» on volcanoes of the world and Kizimen volcano (Russia)
}

\author{
Alexandra Shakirova*, Pavel Firstov \\ Kamchatka Branch of Federal Research Center of the United Geophysical Survey, Russian Academy \\ of Sciences, Petropavlovsk-Kamchatsky
}

\begin{abstract}
The squeezing of viscous lava flows or blocks on an extrusive dome during eruptions of andesitic and dacitic volcanoes is accompanied by volcanic earthquakes the seismic mode «drumbeats». The features of this mode are the quasi-periodicity of the volcanic earthquakes appearance for a long time, uniform waveforms and close VE magnitudes. This mode shows surprisingly the equilibrium behavior of a volcanic eruption.
\end{abstract}

\section{Introduction}

The squeezing of viscous lava flows and blocks on extrusive domes during eruptions of andesitic and dacitic volcanoes is accompanied by sequences of volcanic earthquakes (VE) - multiplets. Multiplets were observed on the volcanoes: St. Helens, North America, the Cascade Range, the eruption of 1984, 2004-2005; Redoubt, Aleutian Islands, 1989; Soufriere Hills, Lesser Antilles, Montserrat Island, 1995-1997; Pichincha, South America, Western Cordillera, 1999; Kizimen, Russia, Kamchatka Peninsula, 2010-2013.

Earthquakes within a single multiplet had a well-defined quasi-period between the VE with duration from fractions to several minutes, as well as similar waveforms and small variations of magnitudes. For a well-marked quasi-period of VE, this mode called «drumbeats» [1]. According to the modern VE classification, waveforms suggest their attribution to hybrid and long-period (LP) earthquakes [2]. Hybrid earthquakes characterized by the high frequency $f \sim 3-10 \mathrm{~Hz}$ in the head and a well-pronounced code of wave. This form of recording is due to the rock destruction caused by the influence of magma pressure or fluid with the formation of a crack and its further filling with the gas

*e-mail:shaki@emsd.ru 
component or fluid released from the magma. LP, with foci in close proximity to the day surface, have a lower frequency $f \sim 1-5 \mathrm{~Hz}$.

\section{Features of «drumbeats» on the andesitic and dacitic volcanoes of the world}

Extrusive eruption St. Helens volcano in October 2004 - May 2005 was accompanied by hybrid micro-earthquakes (Fig. 1a) with $\mathrm{M} \leq 2$ and a quasi-periodicity of 3-300 s [1,3]. Therefore they were named «drumbeats». Registered at $12 \mathrm{~km}$ from the crater, the VE had in the head part the frequency $f \sim 4-10 \mathrm{~Hz}$ and the frequency codes of the wave's $f \sim 1 \mathrm{~Hz}$. With an accuracy of determination of $\sim 100$ meters, their hypocenters were located at depths of about one $\mathrm{km}$ around or under an extrusive dome [4].

Similar seismic conditions were recorded after a catastrophic eruption St. Helens volcano in 1980. In 1984 the micro-earthquakes foci occurred during the 12-hour period in September 1984 are located in a small volume with a diameter of $\sim 30 \mathrm{~m}$ under the lava dome. Presumably, the mechanism of micro-earthquakes was the high strain rates in the magmatic channel during extrusion squeezing [5].

During eruption Redoubt volcano in 1989 - 1990 «drumbeats» micro-earthquakes with a quasi-periodicity of ten seconds to seconds were recorded also, associated with squeezing of extrusion, as indicated by hypocenters associated with the construction of the volcano at depths above sea level. LP earthquakes with $\mathrm{M}<1.8$ represented most of the events, hybrid earthquakes were also recorded. At a distance of $8 \mathrm{~km}$ from the crater, the maximum of the amplitude spectrum was on the frequency $f \sim 1.3-2 \mathrm{~Hz}$. The manifestation of seismicity was due to an increase in pressure because of the introduction of a fresh portion of magma. It led to the cracking of the hardened material of the extrusion external parts [6].

During the eruption Redoubt volcano in 2009 were recorded six VE multiplets, three of which preceded large explosive eruptions. The duration of the multiplets varied from one hour to several days, and they consisted of tens to thousands of LP and hybrid microearthquakes with $\mathrm{M}<1.7$ (Fig. 1b) [7]. At a distance of $3 \mathrm{~km}$ from the crater, the maximum of the power spectral density (PSD) of such earthquakes was with frequency range $f=1-7$ $\mathrm{Hz}$ with a spectral peak at a frequency $f \sim 2.5 \mathrm{~Hz}[8]$.

A large number of VE were recorded on the Soufriere Hills volcano from August 1995 to August 1996. Lava dome was squeezed simultaneously. More than 300000 hybrid earthquakes with $\mathrm{M}<3$ and quasi-periodicity from one second to tens of minutes were recorded (Fig. 1c). Their hypocenters were confined to the body of a volcano and located under a crater at a depth of less than $1 \mathrm{~km}$. In some cases two types of earthquakes with different quasi-periodicity, different waveforms and amplitudes, were simultaneously recorded for several hours. The maximum of the energy spectrum of these VE was in the frequency range $f \sim 1.5-4.5 \mathrm{~Hz}$ at a distance of one $\mathrm{km}$ from the crater [9].

Before a strong explosive eruption Pichincha volcano on September 26, 1999 for 17 days was recorded swarm, consisting of more than 1000 LP earthquakes (Fig. 1d). In September 28, a new extrusive dome was seen in the crater of the volcano; squeezing of dome was also accompanied by the «drumbeats» mode. The onset of the VE began synchronously with the surface deformation, which indicated an increase in pressure in the volcano, caused by the introduction of magma [10]. 




Fig. 1. An example of recording drumbeats earthquakes on volcanoes: a - St. Helens, October 20, 2005 [11]; b - Redoubt, March 27, 2009 [12]; c - Soufriere Hills, 1995 [12]; d - Pichincha, December 2, 1999 [10]; e - Kizimen, September 14, 2011 [14]

Table 1. Characteristics of «drumbeats» mode for andesitic and dacitic volcanoes.

\begin{tabular}{|c|c|c|c|c|c|}
\hline Volcano & $\begin{array}{c}\text { Type of } \\
\text { earthquakes }\end{array}$ & Quasi-period & $\begin{array}{c}\text { Duration of } \\
\text { registration }\end{array}$ & Frequency, Hz & $\begin{array}{c}\text { Magnit } \\
\text { ude }\end{array}$ \\
\hline St. Helens & Hybrid & $30-300$ & $\begin{array}{c}1980-368 \\
\text { days; } \\
2004-2007\end{array}$ & $\begin{array}{c}0.3-5 \mathrm{~Hz} ; \\
4-10, \text { peak } 1 \mathrm{~Hz}\end{array}$ & $\mathrm{M} \leq 2$ \\
\hline Redoubt & LP, Hybrid & $\sim$ tens of & $\begin{array}{c}\sim 4.5 \text { months in } \\
1989 \text { г.; }\end{array}$ & $\begin{array}{c}1-7, \text { peak } 2.5-2.7 \\
\mathrm{~Hz}\end{array}$ & $\mathrm{M}<1.8$ \\
& & seconds & $\mathrm{M}<1.7$ \\
& & & $\begin{array}{c}2010 \text { г. } \\
\text { Sonth in } 2009-\end{array}$ & \\
\hline Hills & Hybrid & from 1 second & $\sim 1$ year & $1.5-4.5 \mathrm{~Hz}$ & $?$ \\
\hline Pichincha & LP minutes & $10-200 \mathrm{~s}$ & $\sim 2.5$ months & $\sim 2$ & $?$ \\
\hline Kizimen & LP, Hybrid & $8-90 \mathrm{~s}$ & $\sim 15$ months & $\begin{array}{c}1.5-5.0, \text { peak } 1.8 \\
\text { и } 3.0 \mathrm{~Hz}\end{array}$ & $\mathrm{M} \sim 0.4$ \\
\hline
\end{tabular}

During the eruption of the Kizimen volcano in 2010-2013 more than 500000 of hybrid and LP earthquakes recorded for 16 months [13]. Its quasi-periodicity varied from second to several minutes (data from the nearest telemetry seismic station «Kizimen», «KZV», Kamchatka Branch of Federal Research Center of the United Geophysical Survey, RAS, (Fig. 2), located in $2.5 \mathrm{~km}$ from the crater). Duration of multiplets varied from an hour to several tens of days.

At the beginning of the eruption, when extrusion appeared in the crater, short VE multiplets were recorded with energy classes $K_{s}=2-3$. Long multiplet of the most powerful $\mathrm{VE}\left(\mathrm{K}_{\mathrm{s}}=3-5.5\right)$ with a quasi-periodicity of 8 to 90 seconds was recorded in May-June, 2011. In July-October multiplet consists of many «drumbeats» earthquakes (Fig. 1e) with $\mathrm{K}_{\mathrm{s}}=4.0-5.5$ with a quasi-periodicity $\leq 2 \mathrm{~min}^{-1}$. From October 11, 2011, against the background of the previously observed VE weaker micro-earthquakes with amplitude $\mathrm{A}=$ $0.5 \mu \mathrm{m} / \mathrm{s}$ with with a quasi-periodicity $<2 \mathrm{~min}^{-1}$ began recorded. In early 2013 , weaker «drumbeats» earthquakes also accompanied the extrusion dome squeezing. The maximum 
power spectral density for all these VE was in the range of $f \sim 1.5-5.0 \mathrm{~Hz}$ with a spectral maximum of $f \sim 1.8 \mathrm{~Hz}[14,15]$.

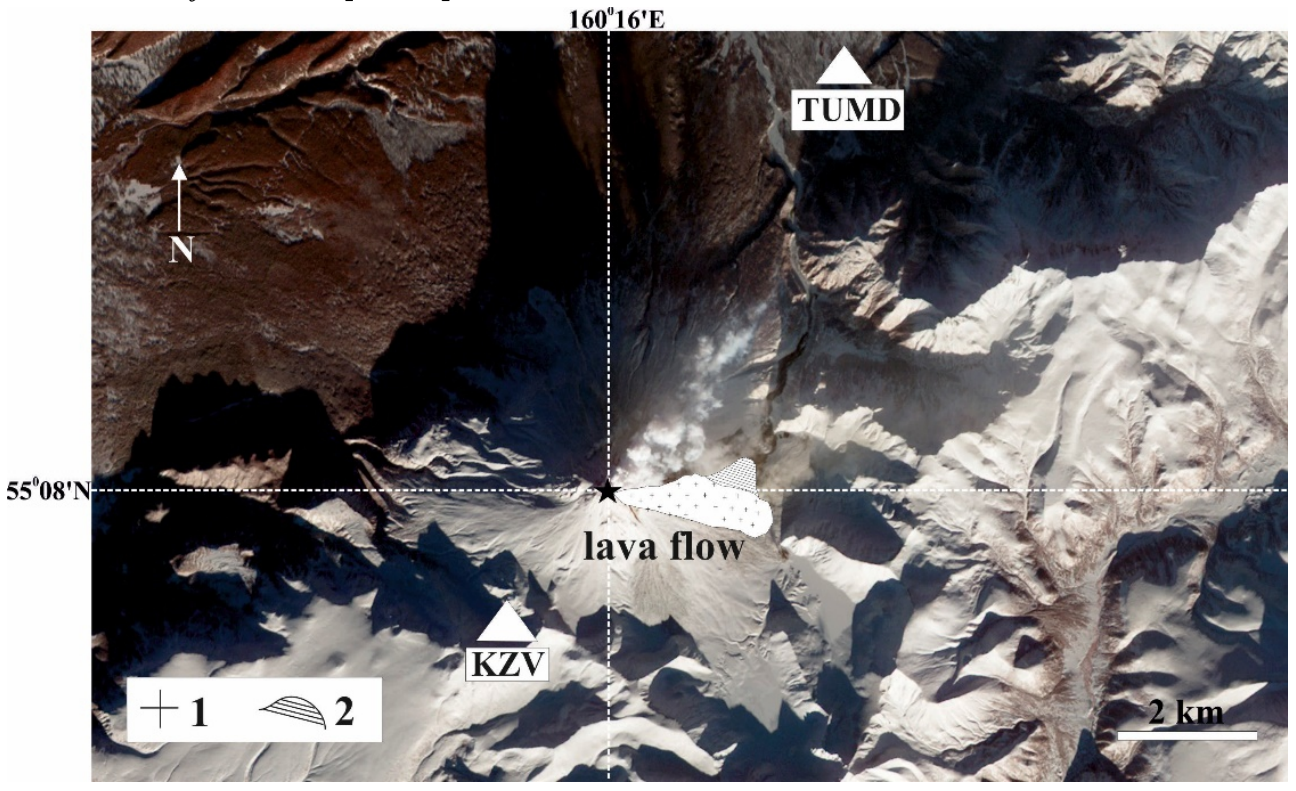

Fig. 2. Seismic stations KZV and TUMD in the Kizimen volcano area and position of lava flow in 2013. 1 - the main body of the flow, 2 - the second «tongue» of the flow [https://earthobservatory.nasa.gov/images/76945/fire-and-ice-at-kizimen-volcano]

\section{Features of «drumbeats» mode on Kizimen volcano}

Multiplets of hybrid earthquakes with $\mathrm{K}_{\mathrm{s}}=3-5.5$ and quasi-periodicity of 8 to 90 seconds were recorded during the movement of the first powerful lava flow tongue in August and September 2011. As a rule, the «drumbeats» mode is associated with squeezing extrusive domes. In addition, «drumbeats» earthquakes accompany the movement of the viscous andesite lava flows, as on the Kizimen volcano.

To verify this observation, the differences in introductions of P-wave between «TUMD» (broadband digital seismic station in $6 \mathrm{~km}$ from Kizimen volcano, Kamchatka Branch of Federal Research Center of the United Geophysical Survey, RAS) and «KZV» station ( $\mathrm{P}_{\text {TUMD }}-\mathrm{P}_{\mathrm{KZV}}$ ) (Fig.2 ) were considered. The $\mathrm{t}_{\mathrm{S}-\mathrm{P}}$ time was compared for both stations for six dates when the micro-earthquakes of the «drumbeats» mode registered with clear S- and Pwaves arrivals. In figure 3 shown that statistically significant changes in seismic wave arrivals observed at these two seismic stations. An increase in $\mathrm{t}$ s-p on «KZV» from 0.7 to $1.5 \mathrm{~s}$ with a RMS error $\sigma=0.2 \mathrm{~s}$, and a decrease in $\mathrm{t}_{\text {TUMD }} \mathrm{t}_{\mathrm{KZV}}$ from 0.9 to $0.5 \mathrm{~s}$ and $\sigma=0.1$ $\mathrm{s}$ indicate that earthquakes epicenters regularly move away from «KZV» and approaching the «TUMD» station. In this case, the spatial location of the lava flow and seismic stations (Fig. 2) clearly indicate that the micro-earthquakes of the «drumbeats» mode were result of a viscous lava flow front moving.

Furthermore, epicenters for the 35 strongest earthquakes for the period of July 29 October 1, 2011 with energy class $3<\mathrm{K}_{\mathrm{s}}<6$ were localized near the contour of the lava 
flow, with a source depth of $1.4 \pm 0.5 \mathrm{~km}$ asl. The estimate of the mean-square error in determining the coordinates of the epicenters is $0.7 \mathrm{~km}$ in latitude and $2.9 \mathrm{~km}$ in longitude. On the vertical section seen that the earthquake foci are grouped on the day surface of the volcano slope.

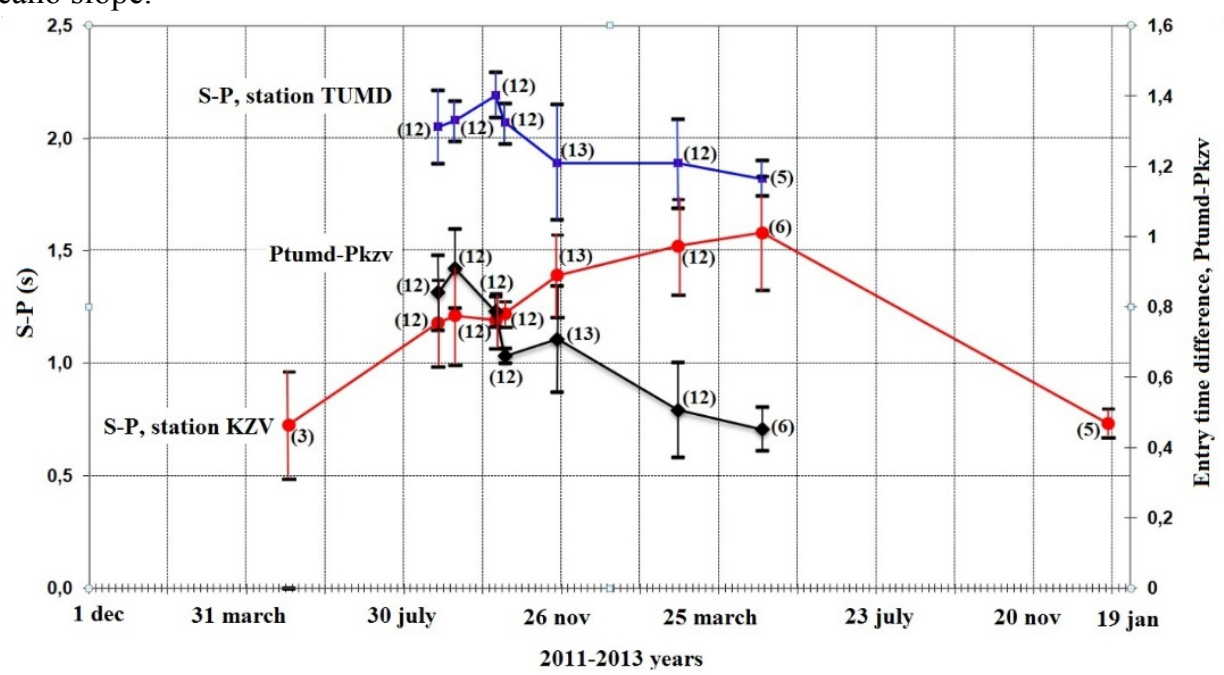

Fig. 3. Changes in S-P and differences in P-waves arrivals times at seismic stations KZV and TUMD in May 30, 2011 - February 24, 2012

\section{Some ideas about the mechanism of the emergence of «drumbeats»}

Viscous magma, moving to the surface through the channel of the volcano, affects the host rocks. With a low rate of magma intake, a stable equilibrium created, causing quasiperiodic «drumbeats» micro-earthquakes. Earthquake mechanisms are stick-slip and are associated with the deformation of the dome of a volcano $\left[\begin{array}{ll}1,3 & 3\end{array}\right.$. An alternative mechanism of the «drumbeats» is the degassing of the upper part of the igneous column. Under the influence of pressure of magma or fluid, the destruction of the geological environment occurs with the formation of a crack, which is filled with the gas component or fluid released from the magma $[7,10,13]$.

\section{Conclusion}

«Drumbeats» earthquakes are observed during eruptions of andesitic and dacitic volcanoes when extrusive dome squeezing. Clear $\mathrm{P}$ and $\mathrm{S}$ waves coming from earthquakes with hypocenters in the volcano's body indicate that they are caused by the fragile destruction of the extrusion or the host rocks due to the intrusive magmatic body. Such earthquakes sometimes precede explosive eruptions.

The emergence of the three types «drumbeats» on Kizimen volcano coincided with the squeezing of the extrusion and with the formation of the first and second viscous lava flow tongues, indicate that such regime can occur during the movement of viscous flows of 
andesitic lava $[14,15]$. It is possible that the emergence of multiplets should be regarded as a process of self-oscillations of the relaxation type. This idea requires a detailed study, which the authors will implement in the future.

The «drumbeats» mode is a unique indicator of the physical processes that accompany the squeezing of viscous andesite magma and its parameters can be useful for predicting the development of volcanic activity.

\section{References}

1. S.C. Moran, S.D. Malone, A.I. Qamar, et al., A Volcano Rekindled: The Renewed Eruption of Mount St. Helens, 2004-2006, Ch. 2 (2008)

2. S.R. McNutt, Seismic monitoring and eruption forecasting of volcanoes: A review of the state-of-the-art and case histories (1996)

3. M.R. Iverson, D. Dzurisin, C.A. Gardner, et al., Nature, 444 (2006)

4. P.H. Stephen, D.N. Robert, C.M. Seth, A Volcano Rekindled: The Renewed Eruption of Mount St. Helens, 2004-2006, Ch. 5 (2008)

5. M. Fremont, S.D. Malone, J. Geophys. Res., 92 (1987)

6. R.R. Cornelius, B. Voight., J. Volcanol. Geotherm. Res., 62 (1994)

7. J.A. Power, J.C. Lahr, R.A. Page, et al., J. Volcanol. Geotherm. Res., 62 (1994)

8. H. Buurman, E.W. Michael, G. Thompson., J. Volcanol. Geotherm. Res., 259 (2013)

9. R.A. White, A.D. Miller, L. Lynch, et al., Geophys.Res.Lett., 25, 19 (1998)

10. A.A. Garcia, H. Kumagai, P. Samaniego, et al., J. Volcanol. Geotherm. Res., 161 (2007)

11. R.S. Matoza, M.A. Garce's, B. A. Chouet, et al., J. Geophys. Res., 114 (2009)

12. C.J. Carlisle. A thesis submitted in partial fulfillment of the degree of Master of Science in Geophysics Boise State University (2013)

13. C.A. Rowe, C.H. Thurber, R.A. White, J. Volcanol. Geotherm. Res., 134 (2004)

14. P.P. Firstov, A.A. Shakirova, J. Volcanol. Seismol., 8, 4 (2014)

15. A.A. Shakirova, Research in Earth Sciences (2012) (RUS) 